\title{
La solidaridad familiar. La participación de la nobleza leonesa en la guerra civil de Portugal (1245-1247)*
}

\author{
Inés Calderón Medina \\ CEPESE-Universidade do Porto
}

RESUMEN: En este trabajo se analiza el panorama nobiliario leonés para explicar la actuación del infante Alfonso de Castilla (futuro Alfonso X) en la guerra civil que enfrentaba a Sancho II de Portugal con su hermano, el futuro Alfonso III. A través de la prosopografía se reconstruye la red de parentesco que une a los nobles leoneses y gallegos, que acompañaron al infante, con la nobleza partidaria de don Sancho. Se demostrará que, ante la alarma lanzada por los parientes lusos, la solidaridad familiar nobiliaria provocó la participación de los nobles leoneses y gallegos en la guerra y el apoyo del infante don Alfonso, ante la negativa de su padre, Fernando III.

\section{Palabras clave: Alfonso X; Sancho II de Portugal; Alfonso III de Portugal; Nobleza leonesa; Solidaridad familiar nobiliaria; Leiría.}

\section{Family Matters: Noblemen from the Kingdom of Leon in the Portuguese Civil War (1245-1247)}

ABSTRACT: In this article I examine Leonese nobility networks as a means to explain the involvement by Prince Alfonso of Castille (later King Alfonso X) in the civil war that confronted King Sancho II of Portugal with his brother Prince Alfonso, later Alfonso III of Portugal. Prosopography allows to reconstruct family bonds linking Leonese and Galician noblemen who had joined Prince Alfonso of Castille with their Portuguese counterparts who had rallied behind King Sancho. I will aim to prove that, following the alarm triggered by

* Este artículo se incardina en el proyecto "La nobleza leonesa entre la expansión y la crisis, 1230-1312", que desarrolla la autora dentro del programa de ayudas de movilidad postdoctoral en centros extranjeros, financiado por el Ministerio de Educación del gobierno de España. 
their Portuguese relatives, family bonds prompted Leonese and Galician noblemen to take part in the war and to seek Prince Alfonso of Castille's support, after his father, King Ferdinand III, refused it.

Key words: $\quad$ Alfonso X; Sancho II of Portugal; Alfonso III of Portugal; Leonese nobility; Family bonds among nobility; Leiria.

Son pocas las noticias sobre la actuación del infante Alfonso de Castilla en la guerra civil lusitana que enfrentó a Sancho II con su hermano el conde de Boulogne entre 1245 y 1247. No obstante, la participación de don Alfonso tuvo una gran importancia para el devenir de don Sancho y, como indica Mattoso, determinó la política que Alfonso X tuvo con Portugal durante los primeros años de su reinado ${ }^{1}$. Las fuentes conservadas son escasas y poco elocuentes. La cancillería de don Sancho no refleja la ayuda que el infante Alfonso le prestó ${ }^{2}$, tampoco la documentación regia castellana hace referencia explícita a este acontecimiento; sólo algunos diplomas emitidos por la curia pontificia, otros del infante Alfonso y varios documentos privados aluden a ello. Sin embargo, sospechamos que pudo existir una abundante e interesantísima documentación epistolar nobiliaria que ha desaparecido. La cronística castellana no se detiene en demasía en este suceso: ni siquiera la crónica de Alfonso X describe esta campaña, sólo hace alusión a la llegada de Sancho II a Toledo tras su deposición ${ }^{3}$, y la crónica de la población de Ávila aporta algunos datos. No obstante, la cronística portuguesa posterior recogió la intervención de las tropas leonesas en Leiría, aunque con numerosas imprecisiones ${ }^{4}$.

La parquedad de las fuentes genera numerosas incógnitas que se ciernen sobre la intervención del príncipe castellano y la nobleza de su reino en la guerra portuguesa.Entre estas tenemos las motivaciones, los preparativos, los participantes, los efectivos militares, el desarrollo de los acontecimientos, el posible pacto al que había llegado el infante con Sancho II, etcétera. Analizaremos esta campaña desde una óptica nobiliaria. Utilizando la prosopografía intentaremos descubrir qué nobles participaron en esta incursión y determinar

1 MATTOSO, 2001: 66.

2 BERNARDINO GONÇALVES PEREIRA, V, 2003, (texto policopiado).

3 GONZÁLEZ JIMÉNEZ, 1999, cap VII: 19. Manuel González advierte el error en la cronología de los acontecimientos cometido por el cronista que mezcla los sucesos acaecidos en 1247-1248 del exilio y la muerte de Sancho II y el primer tratado de Badajoz de 1252.

4 Entre las crónicas lusas que informan sobre esta cuestión figuran la crónica de cinco reyes, la Crónica portuguesa de 1419. DE MAGALHÃES BASTO 1945. ALMEIDA CALADO, 1998. 
el parentesco y los intereses que los unían a la nobleza lusitana, porque sospechamos que estudiando el estrato nobiliario es posible explicar aspectos determinantes de esta expedición del hijo de Fernando III en tierras lusas.

\section{CONSIDERACIONES SOBRE LA INTERVENCIÓN MILITAR}

Son muchos los historiadores que tanto desde la óptica castellana como desde la portuguesa han estudiado este episodio de la juventud de Alfonso $X^{5}$. Mondéjar narra esta campaña aunque con numerosas inexactitudes ${ }^{6}$. Ballesteros la menciona pero no se detiene en su análisis ${ }^{7}$. Julio González estudia la preparación de la campaña por parte del infante y su intervención en la «desgracia de don Sancho» ${ }^{8}$. González Jiménez explica esta incursión en el reino luso como una cuestión ideológica, en la que Alfonso de Castilla defendía la autoridad regia por encima del Papado y de su injerencia en los asuntos nacionales ${ }^{9}$, como plasmaría posteriormente en Las Partidas ${ }^{10}$. Asimismo, señala que posiblemente el monarca portugués habría prometido entregar al infante don Alfonso el territorio del Algarbe como pago por su ayuda ${ }^{11} \mathrm{y}$, por ello, el príncipe castellano entraría en Portugal.

Tradicionalmente se ha tratado la campaña del infante don Alfonso en Portugal como una empresa para ayudar a Sancho II; sin embargo, Gonzaga de Azevedo afirmaba que estaba destinada a la conquista del territorio portugués ${ }^{12}$. Ante la protección de don Alfonso sobre Sancho II, el historiador luso sospecha que el infante pudiera tener aspiraciones al trono de Portugal. José Varandas defiende la hipótesis de que la actuación del castellano no era desinteresada en defensa de los intereses de Sancho II, sino que es probable que en el caso de que el rey de los lusos muriera sin descendencia y de que las huestes lograran alcanzar una posición fuerte, la corona portuguesa podría ser un objetivo apetecible para el infante de Castilla. Argumenta que en la carta enviada a Inocencio IV don Alfonso no defiende la posición de Sancho II, ni

5 GONZÁLEZ. 1980, (I): 272-275. GONZÁLEZ JIMÉNEZ. 1999b: 27-30. BALLESTEROS BERETTA, 1984: 74. GARCÍA FERNÁNDEZ, 1998, (2): 901-943. SALVADOR MARTÍNEZ, 2003: 106-107. Desde la óptica portuguesa han analizado esta intervención FERNANDES, 2006. VENTURA, 1996, (III): 106- 123.

6 MONDÉJAR, 1777, capítulo XVI: 24- 27.

7 BALLESTEROS BERETTA, 1984: 74.

8 GONZÁLEZ J. 1980, (I): 272-275.

9 GONZÁLEZ JIMÉNEZ, 4 (Sevilla, 2004-2005): 19-34, GONZÁLEZ JIMÉNEZ, (Porto 2000): 1-24.

10 GONZÁLEZ JIMÉNEZ, 2006: 198- 201.

11 GONZÁLEZ JIMÉNEZ, 1999: 27- 30.

12 GONZAGA DE AZEVEDO, 1944: 111. 
siquiera lo menciona, sino que sólo se ocupa de proteger su patrimonio e intereses en Portugal ${ }^{13}$. Hermenegildo Fernandes apunta a que el trono de don Sancho tenía varios pretendientes: el conde de Boulogne, el infante de Portugal Pedro Sanches y don Alfonso, infante de Castilla ${ }^{14}$. No duda de que el infante don Alfonso ambicionaba extender la hegemonía castellana a Portugal, como habría ideado su abuela Berenguela que acababa de morir ${ }^{15}$.

Gil de Zamora y la Crónica de 1344 afirman que Sancho II había prometido dar su reino a Alfonso X; sin embargo, esta manda no fue recogida en su testamento emitido en Toledo en $1248^{16}$. Mattoso señala que esta cesión pudo haberse hecho en privado y que éste sería el motivo que posteriormente utilizaría Alfonso X para argumentar su posesión del Algarbe ${ }^{17}$. Bien es cierto que antes de 1245 el príncipe Alfonso había recibido varios castillos en territorio lusitano, aunque se desconoce el momento en el que los obtuvo y su emplazamiento. En las cartas enviadas a Inocencio IV, don Alfonso se queja de la actuación de las tropas del conde de Boulogne sobre sus castillos y propiedades, que estaban siendo arrasadas. Ante las quejas del príncipe de Casti1la, el Papa le contestó en julio de 1246 que había ordenado al conde de Boulogne que dejara de atentar contra sus bienes, además le dice que si el rey diese pruebas de poder gobernar, le entregaría el reino de nuevo ${ }^{18}$. Además de estas razones en las que estaban en juego los intereses del infante don Alfonso, sospechamos que pudieron existir otras motivaciones personales y relacionadas con la presión de la nobleza leonesa y gallega, que estaba estrechamente vinculada con los nobles partidarios de Sancho II de Portugal.

Barajamos la hipótesis de que los intereses personales y familiares nobiliarios atravesaron fronteras y la solidaridad familiar influyó e, incluso, provocó la participación del heredero de León y Castilla en la guerra civil portuguesa. Probablemente se trató de una conjunción de intereses entre el infante don Alfonso de Castilla y los nobles leoneses y gallegos, que estaban viendo amenazados los intereses que sus parientes y ellos mismos tenían en Portugal. Es necesario conjugar este abanico de motivaciones para explicar la intromisión del futuro Alfonso X en la guerra civil que enfrentaba a los lusos.

\footnotetext{
13 VARANDAS, 2004: 402

${ }^{14}$ FERNANDES, 2006: 261.

15 FERNANDES, 2006: 261.

16 VARANDAS, 2004: 182.

17 MATTOSO, 1993, 2: 132.

${ }^{18}$ GONZAGA DE AZEVEDO, 1944: 113.
} 


\section{LA CRISIS DE PORTUGAL (1245- 1247)}

Para comprender la participación leonesa en la guerra civil lusitana, es preciso retrotraerse hasta los comienzos del reinado de Sancho II. El Capelo fue un rey débil, rodeado de una poderosísima nobleza que aprovechó su debilidad, desde su llegada al trono, para aumentar su poder político y patrimonial. Los abusos de la nobleza fueron en aumento ${ }^{19}$. Los nobles atacaban de manera habitual las propiedades eclesiásticas y usurpaban el patrimonio regio, lo que originaba una gran inestabilidad social además del debilitamiento del poder real. A partir de 1236 la situación empeoró y la turbación se apoderó del reino, pues la violencia y los enfrentamientos internobiliarios eran constantes $^{20}$. Ante esta turbación los obispos de Oporto y Braga informaron al Papado, denunciando la incapacidad del monarca para controlar la situación y mantener la justicia en el reino. Así se puso en marcha la maquinaria para deponer al rey legítimo de los lusos y preparar la llegada al trono de su hermano, el conde de Boulogne ${ }^{21}$.

En 1241 Sancho II casó con Mencía López de Haro. Este matrimonio no fue bien recibido por los enemigos de don Sancho, ya que si la pareja engendraba descendencia, las pretensiones al trono del conde Alfonso se desvanecerían de inmediato ${ }^{22}$. En 1244 el conde de Boulogne denunció la consanguinidad del matrimonio a Inocencio IV. Finalmente, el Papa emitió el 24 de julio de 1245 la bula Grandi non inmerito por la que declaraba a don Sancho rex inutilis para las funciones de gobierno y nombraba a su hermano el infante don Alfonso, conde de Boulogne, curador del reino ${ }^{23}$. El conde Alfonso se preparaba para dirigirse a Portugal.

En 1245 los bandos nobiliarios estaban bien definidos ${ }^{24}$. Entre los opositores de Sancho II se encontraban las grandes familias de Sousa, Ribeira, Alburquerque, Valadares, Baião, y algunos Correia, además de los linajes de caballeros Portocarrero y Briteiros y Rodrigo Sánches, el bastardo de Sancho I, que capitaneaba el partido del conde de Boulogne ${ }^{25}$. Otros hijos de Sancho I como don Pedro Sánches, infante de Portugal, y doña Teresa, antigua reina de

19 Véase MATTOSO, 6, (Coimbra, 1984): 7- 25.

${ }^{20}$ Véase FERNÁNDES, 2006: 221-232.

${ }^{21}$ COSTA SOUSA, A.D, 1963, n. 345-347, 516.

22 El matrimonio con la dama castellana fue mal recibido en Portugal, las Crónicas Breves de Santa Cruz de Coimbra y la Crónica de Portugal de 1419 apuntan al matrimonio como el punto de inflexión de la ruptura de su reinado, "E començou a por ser muito bom rei e justiciero mas houve maus conselheiros. E depois, dali em adiante não foi justiceiro. E saiu do mando da rainha D. Berenguela sua tia e casou-se com Mencia Lopez. E desde ali foi para mal" FERNANDES, 2006: 253.

${ }^{23}$ SOUSA COSTA, n 547.

${ }^{24}$ VENTURA, 1993, vol 3: 106

25 VENTURA, 1993, 113, nota 87. 
León ${ }^{26}$, se unieron al bando de don Alfonso. Leontina Ventura señala que estaban contra Sancho II aquellos que en 1211 habían estado contra Alfonso II; es decir, que en ambos casos se oponían a la centralización del poder ${ }^{27}$. A favor del rey legítimo se encontraban los Soverosa, los Tougues y los Riba de Vizela, que le fueron fieles hasta el final. Entre las figuras más destacadas de este partido destacan Martín Gil de Soverosa, que dirigía las tropas ${ }^{28}$, su hermano Vasco Gil $^{29}$ y el padre de ambos, Gil Vasques de Soverosa ${ }^{30}$, además de su pariente Suero Gomes de Tougues ${ }^{31}$. Todos ellos aportaban a la defensa de don Sancho a sus vasallos y clientes.

La guerra ya era abierta ${ }^{32}$. En el verano de 1245 las huestes se habían enfrentado cerca de Oporto, donde Martín Gil de Soverosa venció a Rodrigo Sánches en la llamada «lid de Gaia» ${ }^{33}$. Tras la deposición de don Sancho, su hermano desembarcó en Lisboa entre los últimos días de diciembre y los primeros de enero de 1246. Desde su llegada el conde de Boulogne dirigió sus ataques a Coimbra, principal bastión de Sancho II $^{34}$. Durante el tiempo que duró el asedio de la ciudad, la reina Mencía fue raptada, en el verano de 1246, y recluida en la fortaleza de Ourém, que pertenecía a sus arras ${ }^{35}$. Tras fracasar en su intento de conquista de Coimbra, don Alfonso se dirigió a Óbidos y Leiría. El conde de Boulogne entró en Leiría el 2 de abril de 1246, ante cierta oposición de la ciudad. En este encuentro murieron algunos de los principales partidarios de don Sancho, como Suero Gomes de Tougues y Lourenço Fernandes de Gundar ${ }^{36}$ y otros, como Vasco Gil de Soverosa, fueron capturados ${ }^{37}$.

26 VENTURA, 1993, 113-114.

27 VENTURA, 1993, 114.

${ }^{28}$ Martín Gil era fruto del primer matrimonio de Gil Vasques de Soverosa y Maria Aires de Fornelos, antigua concubina de Sancho I. Era hermano de Teresa Gil de Soverosa, la última concubina de Alfonso IX.

29 Vasco Gil era hijo del segundo matrimonio de Gil Vasques de Soverosa y Sancha González de Orvaneja.

30 Sobre los acontecimientos de la guerra civil portuguesa, véase VENTURA, 2006: 73-84.

${ }^{31}$ Este bando nobiliario estaba fuertemente ligado por lazos de parentesco, ambos descendían de Gonçalvo Mendes de Sousa y de Urraca Sanches de Barbosa, puesto que las hijas de este matrimonio, Elvira Gonçalves casó son Suero Mendes de Tougues y su hermana, Teresa Gonçalves con Vasco Fernandes de Soverosa, que son los abuelos de Soero Gomes y Martín Gil. Rodrigo Froilaz emparentaría con ellos al casar con Chamôa Gomes.

${ }^{32}$ Sobre la guerra civil véase VENTURA, 2006: 73- 84.

33 Sobre los acontecimientos de la guerra civil, VARANDAS, 2004: 391-407. Don Rodrigo y don Martín eran medio hermanos, pues ambos eran hijos de María Aires de Fornelos. Rodrigo Sanches murió en la lid de Gaia.

34 VENTURA, 1996: 118 Leontina ventura afirma que las tropas de Sancho permanecieron en Coimbra entre enero de 1246 a Junio de 1247.

${ }^{35}$ MATTOSO, 1981: 279-283

${ }^{36}$ Los hijos de don Lourenço, Pedro, García y Gil Lourenço de Gundar habían participado en la toma Murcia junto al infante Alfonso de Castilla. TORRES FONTES, 1973, III: 37. 
La guerra se encontraba en tablas, pues Sancho II atacaba el abastecimiento de Leiría y el conde no tenía las fuerzas suficientes para asaltar Coimbra. Empezaba el período más violento de la guerra. Los objetivos eran controlar la Beira y la Extremadura. Fue en este momento cuando el Capelo solicitó la ayuda del infante castellano, que comenzó a preparar su entrada en Portugal. Así, el 13 de enero de 1247 Sancho II, Martín Gil de Soverosa y el infante Alfonso de Castilla, junto a sus ejércitos estaban en las puertas de Leiría para hacer frente a las tropas del conde de Boulogne ${ }^{38}$.

\section{LOS PREPARATIVOS DE LA INTERVENCIÓN DEL INFANTE DE CASTILLA}

La inestabilidad del reino luso era bien conocida por los leoneses y por el rey de Castilla desde su comienzo. Las noticias del agravamiento de la situación llegaron con gran celeridad a oídos del hijo de Fernando III, que comenzó a diseñar su intervención.

\section{La vía diplomática}

Don Alfonso había recibido en territorio portugués varios castillos y otros bienes, pero se desconoce cuáles eran y en qué momento le fueron entregados. Al parecer, los bienes del infante castellano estaban siendo atacados con máquinas de guerra que habían causado gran devastación, por ello, el hijo de Fernando III elevó su queja al pontífice Inocencio IV ${ }^{39}$. El Papa se dirigió al conde Boulogne, ordenándole no atacar los bienes de don Alfonso de Casti$1 a^{40}$. Pocos días después el Pontífice pedía al infante Pedro de Portugal, hijo de Sancho I, que interviniese en la contienda en apoyo del conde de Boulogne, que debía hacerse cargo del reino, como la curia romana había ordenado ${ }^{41}$.

Parece que con esta intermediación ante el papado, don Alfonso consiguió proteger sus propiedades lusitanas, pero su interés por ayudar a don Sancho continuaba, además la preocupación del castellano creció al saber que Pedro de Portugal se uniría a las tropas del conde de Boulogne. Don Pedro era un enemigo poderoso y un hábil político, bien conocido en tierras leonesas ${ }^{42}$; su

37 VENTURA, y GOMES, 28 (Coimbra, 1993): 166.

38 VENTURA, y GOMES, 28 (Coimbra, 1993): 167.

${ }^{39}$ Se conoce esta queja hecha por el infante a través de la respuesta papal, DE MANUEL RODRÍGUEZ, 1800: 477.

40 DE MANUEL RODRÍGUEZ, 1800: 477.

${ }^{41}$ VARANDAS, 143.

42 Acerca de la carrera política desarrollada por Pedro de Portugal en León, véase CALDERÓN MEDINA, 2011a: 230- 240. 
participación en la contienda, sin duda, inclinaría la balanza a favor del conde. Ante las noticias que llegaban del reino vecino, el infante Alfonso decidió actuar manu militari, muy probablemente para asegurar sus bienes e intereses políticos - y quién sabe, si con la ambición de lograr el trono-, pero también los de la nobleza leonesa y gallega que estaban en torno a él y cuyos parientes portugueses estaban viendo amenazado su estatus y su patrimonio ${ }^{43}$.

\section{La intervención militar}

Don Alfonso estaba en el campamento asediando Jaén cuando le llegaron las noticias sobre el agravamiento de la situación lusitana. Entonces, probablemente se percató de que la vía diplomática no resolvería la cuestión y de que era precisa una intervención militar. El infante se replegó al reino de León, donde ejercía el gobierno desde $1240^{44}$, y donde había trazado relaciones de amistad y fidelidad con la nobleza. Esta vinculación a León le permitiría contar con el apoyo suficiente para buscar los recursos necesarios y llevar a cabo esta campaña. En agosto de 1246 se encontraba en Zamora, donde donó Sarria a la Orden de San Juan «quando don Alfonso vino de Jahén sobre fecho de don Rodrigo Gomez et de Portogal» ${ }^{45}$. Aquel 15 de agosto, el hijo de Fernando III estaba acompañado por los obispos de León, Coria, el maestre de Alcántara, y por los nobles castellanos Lope López de Haro, Nuño González de Lara, Alfonso Téllez de Meneses, el gallego Rodrigo Gómez de Traba, y por los leoneses Rodrigo Froilaz, Rodrigo Fernández de Valduerna, Pedro Ponce y el asturiano, Álvar Díaz de Noreña; además de don Rodrigo Alfonso, hijo de Alfonso IX y de la portuguesa Aldonça Martins de Silva.

Parece que pocos días después de sofocar la revuelta de Rodrigo Gómez, el infante se dirigió a Ávila, pidiendo la participación del concejo en la campaña que estaba preparando para actuar en Portugal. Su padre, Fernando III, se oponía tajantemente a esta injerencia en el conflicto portugués y envió una orden a los caballeros de la ciudad para que no acompañaran a su hijo en esta empresa. Los caballeros de Ávila no se unieron a la hueste por temor al rey,

${ }^{43}$ Sospechamos que existió un importante intercambio epistolar entre los nobles leoneses y sus parientes lusos, que describirían la situación y sus necesidades, pero desafortunadamente no se han conservado.

${ }^{44}$ En 1240 Fernando III entregó a su hijo funciones de gobierno y de representatividad del poder regio en el reino de León, como las tenencias de León y Salamanca. GONZÁLEZ JIMÉNEZ, 2004, 22.

45 GARCÍA TATO, 2004, doc. 75. El diploma está fechado el 15 de agosto de 1246 en Zamora y confirmado por los obispos de León, Coria, el maestre de Alcántara, Lope López de Haro, Nuño González, Alfonso Téllez, Rodrigo Gómez, Rodrigo Froilaz, Rodrigo Alfonso, Rodrigo Fernández de Valduerna, Pedro Ponce y Álvar Díaz de Asturias. 
pero entregaron la mitad de la fonsadera, con la que probablemente se financió parte de la expedición ${ }^{46}$. Ante la negativa del concejo de Ávila, el infante, en septiembre de 1246, se dirigió a los concejos del Valle del Guareña, que se negaban a ir en hueste bajo la seña de Toro, pidiéndoles que le sirvieran del mismo modo que lo hacían a su padre don Fernando ${ }^{47}$.

A pesar de la negativa de varios concejos del reino, don Alfonso contó con la participación de la milicia concejil de Ciudad Rodrigo. En 1268, siendo rey, eximió del pago de varios impuestos a «todos aquellos que moraren en la cibdade que tovieren caballos e armas de corpo e de caballo(...) por el mucho servicio que nos fezieron, et por el servicio que nos fezo el conceio quando eramos infante e entrávamos a Portogal $\gg^{48}$. Probablemente también le sirvieron las ciudades de León y Salamanca, de las que era tenente ${ }^{49}$, aunque no se ha conservado documentación que lo acredite.

Se desconoce si la Iglesia leonesa participó en los preparativos de la campaña. Algunos de los principales obispos del reino de León (Coria, León, y Astorga) estuvieron con don Alfonso en su deambular por el reino en busca de recursos, lo que hace sospechar que pudieran haber hecho algunas aportaciones, aunque esta hipótesis no ha podido ser verificada documentalmente. Sin embargo, sí se constata el apoyo de los principales nobles del reino de León, que habían estado en el círculo más cercano de Alfonso IX hasta 1230.

A pesar de los esfuerzos, parece que los recursos aún no eran suficientes y el príncipe castellano decidió buscarlos más allá de la frontera de León. El 20 de diciembre de 1246 desde Sabugal dirigía una misiva a su futuro suegro,

46 HERNÁNDEZ SEGURA, 1966, 46- 47. «Después de a poco tiempo alçosse don Rodrigo Gomez en Castro Cisneros, e fue el infante don Alfonso, fijo del rey don Fernando, çercarle. Pero quiso Dios e fueron con él el concejo de Avila, e sirviéronle y bien e lealmente, así que ovo de venir don Rodrigo Gómez a mano del infante, e ovo de fazer quanto él mandó. Assí el infante ovo de entrar en Portogal, e el rey don Fernando embió decir a los de Avila que non fuesen y. E por temor del rey non fueron y, e con sabor de servir al infante, la meatad de la fonsadera que avien aver los caballeros diérongela al infante, e non quissieron ellos tomar nada».

47 «De mi infante don Alfonso, hijo del rey don Fernando, a los concejos de san Román, el Afuent del Saugo, e de la fuente de la Peña, e de Villaescusa, e de Castel de la Vid, e de Ordeño, e de Cañizal, e del Olmo, e de Ballesa, e de Bóveda, e de Badiello, e a todos los otros de Val de Garoña, salud. El concejo de Toro se envió querellar, que soledes con ellos venir en hueste, e aguardar su seña, e agora que non queredes venir con ellos. Ende vos mando firmemientre, que todos aquellos que soledes venir con ellos a guardar su seña en tiempo del rey mio padre, a atal cosa como esta, cada que menester vos ovo, que todos vengades con ellos, e aguardedes só sena, e non fagades ende al. E si contra esto alguna cosa queredes decir, por eso non dejedes de venir, mas venid todos en mio servicio, e razonaredes con ellos ante mí; e el que non viniese de cuantos por armas tomar fuese, fincarie por alevoso del rey mio padre, e mio, e al cuerpo, e a cuanto oviese me tornaría por ello. Facta Palencie XXX. die septembris, era de M.CC.LXXXIIII». En DE MANUEL RODRÍGUEZ, 1800, 479.

48 BARRIOS, 1988, doc 5.

49 FERNÁNDEZ CATÓN, 1991, vol 6, docs 2074, 2078. 
Jaime I de Aragón, en la que le pedía que le ayudara en su campaña de Portugal, enviando a su hijo, el infante don Pedro, y a Pedro Cornel con 300 caballeros; al tiempo que le pedía que escribiera al infante don Pedro de Portugal para que retirara su apoyo al conde de Boulogne, que perdería así su principal fuer$\mathrm{za}^{50}$. Asimismo, le emplazaba para determinar el lugar y el día en el que los efectivos militares debían encontrarse para atravesar juntos la frontera lusitana.

El proceso de preparación de esta intervención se dilató durante varios meses. Da la sensación de que el infante y los nobles leoneses y gallegos actuaban desesperadamente en busca de los recursos suficientes, apelando a los concejos, probablemente a los obispos y al rey de Aragón, frente a la negativa de su padre. Parece que don Alfonso pretendía organizar una importante y ambiciosa intervención y no una débil aportación casi anecdótica como parecen transmitir las fuentes. Queda claro que esta expedición era principalmente leonesa, financiada con capital leonés, y ejecutada por las mesnadas de destacados nobles leoneses y gallegos, que fueron el acicate decisivo.

\section{El infante don Alfonso en Portugal}

Parece que aún se dilataron algunos días los preparativos en la tierra de Sabugal, de la que era tenente Rodrigo Froilaz. Se desconoce el momento exacto en el que los ejércitos cruzaron la frontera y su cuantía, aunque suponemos que era una copiosa hueste, ya que el infante entró en Portugal con las mesnadas de los nobles más poderosos de León, además de Diego López de Haro y los aragoneses, dirigidos por el infante don Pedro y por Pedro Cornel.

Tampoco se conoce con exactitud el itinerario que siguieron, aunque una cantiga del gallego Airas Peres de Vuitoron, que había entrado en Portugal con el ejército del infante de Castilla, relata las traiciones de numerosos alcaldes que entregaron los castillos que tenían de manos de Sancho II a su her-

50 «Nos vos enviamos decir que nuestra voluntad era de entrar en Portugal et sobr'esto embiamos- vos rogar que nos embiasses vuestro fijo el infant don Pedro con trezientos caballeros et que don Pedro Cornel viniesse con ellos et vos enbiastes-nos a dizer por don Guillem, vuestro escribano, ... mas ... queriemos que vos embiaredes.....(fi)jo o infant don Pedro et que en esto et en al que aviedes voluntad de fernos ayuda et amor, et nos agradece-vos-lo mucho et noa al fuiza(?) Aviemos en vos et... que trahen pleito entre nos et el conde de Bononia et non sabemos aun si auremos mester, mas quando mester nos fuere embiar-vos-lo emos decir en qual logar et quando .....tovemos todos los caveros rogamos-vos que vengan don Pedro Cornel con vuestro fijo el infant don Pedro et con ellos, et gradecemos-vos mucho. Otrossi de las cartas que embiastes al infant don Pedro de Portugal, que en cosa del mundo non nos podriedes fazer mayor amor que en esto, ca bien sapedes que lamayor ayuda que ha el conde de Bononia el es, et si a perdiere sepades que a perdido todo el reyno». VALLSTABERNER, 1919:14. 
mano. Su relato sitúa a la hueste en la Beira interior en su camino hacia Leiría: narra las deserciones de los alcaldes de Monsanto, Mirialva, Trancoso, Sortelha y Covilhã, lo que podría ser indicativo del espacio por el que se movió la expedición leonesa ${ }^{51}$. El 13 de enero de 1247, las tropas capitaneadas por el heredero de León y Castilla se encontraban a las puertas de Leiría junto a Sancho II y sus partidarios.

\section{Leiría 1247}

Un diploma del fondo de la catedral de Coimbra describe la intervención del infante don Alfonso en la ciudad de este modo:

Item noveris quod modo de novo in istis octavis apparicionis, milites de Castella qui sunt ex parte domini regis et domni Martini iuverunt ad Leirenam et interfeccerunt ibi ultra ducentos homines et alias maxima dampna intulerunt, et nec clericos nec laicus est ausus exire de Leirena nec etiam ad vineas exolendas propter quod citati a vobis non possent ad dies et locum per vos assignatos accedere et quia hoc peccatis exigentibus probatum est alia probacione non indiget ${ }^{52}$.

En el ataque a Leiría las tropas de Sancho II y de Alfonso de Castilla causaron más de doscientos muertos en el bando del conde Alfonso de Boulogne. Además impusieron una fuerte represión entre sus habitantes, tanto es así que no dejaban salir de la ciudad ni a clérigos ni a laicos, ni siquiera para cultivar las viñas. Los escribanos de Coimbra nada dicen de la duración del enfrentamiento, ni de la cuantía, ni de los integrantes de las tropas del infante de Castilla, a los que aluden genéricamente como milites. Años después Gil de Zamora relataría los acontecimientos vividos en Leiría de la siguiente manera:

Ubi vero Infans Aldefonsus regnum Portugalie subintravit cum Legionensium et Castellanorum militia copiosa, cedibus et spoliis, rapinis et direptionibus vacans, usque in Leyrenam pervenit, et fregit ipsius ville fortissimum arrivalium - Dominus etiam Nunio Gundisalvi, quem voluerunt commitere Leyrenenses, Infans nobilis, Baro fortis, ipsos Leyrenenses agressus viriliter et audaciter, quosdam prostravit hastis et alios vero captos ad redemptionis misericordiam reservavit. Variis hinc inde cedibus et direptionibus perpetratis, predictus Infans, tum ratione sententie que ferebatur in omnes Comiti obsistentes ${ }^{53}$.

${ }^{51}$ BREA, 1996, vol 1: 129- 131.

52 Ventura y GoMes, 28 (Coimbra, 1993): doc. 2.

${ }^{53}$ Fita COLOMER, 1884: 308-328. 
La cruenta actuación capitaneada por don Alfonso en tierras lusas tuvo sus consecuencias para quienes participaron en ella. Así, probablemente en febrero de 1247, los obispos de Braga y Coimbra escribieron a los franciscanos de Guarda y Covilhã para que excomulgasen al infante Alfonso y a don Diego López de Haro, Rodrigo Gómez de Traba, Fernando Iohannes de Limia y a los hermanos Rodrigo y Ramiro Froilaz por haber desobedecido la provisión papal al enfrentarse al conde de Boulogne:

In permissione divina archiepiscopus Bracarensis e $\mathrm{D}$ [omingos] eadem electus Colimbrigensis religionis viris et in Christo dilectis de Gardia et de Coviliana Ordinis Fratrum Minorum Guardianis eorumque conventibus suis Dei fidelibus salutem et presentis vite cursum in confessione Christi pro justicia consumare.

Cum nobiles viris dominnus Didacus Lupi domnus R[odericus] Gomecii de Gallecia, domnus Ramirus Froila et domnus Rodericus Froile et domnus Fernandus Johannis de Lima ad impediendum provisionem apostolicam cum domno A[lfonsus] regis Castelle et Legionis primogenito regnum Portugalie sicut accepimus sint ingressi nos qui provisionis eiusdem executores sumus a sumo Pontifice deputati devotioni vestre in virtute obedience predipiendo, mandamus quatinus per vos vel per aliquos fratres vestros ad ipsos vel ad locum ubi ipsi in regno isto fuerint accedentes ex parte domnini Pape et nostra monere curetis eosdem et vassallos et auxiliatores eorum ut ab huiusmidi o domini comitis Bolonie et provisionis de ipso facte regi et regno Portugalie et populis in eo degentibus impedimento se et suos procurent cohibere admonitionem ipsam, coram ipsis et aliis qui affuerit vel si eorum copiam habere forte non potueritis in locis ubi fuerint ut dictum est publicare curetis. Quod si a vobis comoniti resipiscere noluerint presertim cum nos per regnum Castelle et Legionis in multis civitatibus coram populo universo provisionem apostolicam publicantes admonitiones etiam publice contra tales et generaliter proposuerimus ipsos auctoritate nostra in Gardia et in locis allis ubi vobis ire licuerit excomunicatos.

Preterea domnus Fernandum Iohanis et domnum Rodericus Froile prefactos qui olim diocesis Bracarensis hostiliter percurrentes, propter violationes ecclesiarum et rapinas bonorum ecclesiasticorum domni legati et predecessoris nostri archiepiscopi Bracarensis sententias incurrerunt et postmodum prestito juramento vicariis Bracarensis quod super hiis pro quibus excomunicati erant mandatis parerent ecclesie et lesis satisfacerent de comissis ad magnam ipsorum et domini Compostellani instantiam ab eisdem vicariis beneficio absolutionis obtento satisfacere neglexerunt.

Nos justitia exigente ipsos in pristiam excomunicationis sententiam reducimus mandantes vobis quantinus ipsos ex hac etiam causa specialiter denuncientis excomunicationis sententia innodatos mandamus etiam vobis sub prescripti tenori precepti quatinus litteras istas quas mittimus infanti domno A. faciatis ei legi vel ubi ipse fuerit per aliquos ex vobis qui ipsum ex parte nostra diligenter moneant et inducant ad ea que in ipsis litteris continentur qui eciam easdem litteras perlectas retineant in testimonium facte admonitionis et consuerent easdem prout in fine eiusdem littere continetur. Datum apud Leirenam IIII idus Februari ${ }^{54}$.

${ }^{54}$ ANTT. Gaveta XIII, mç 9, doc 1. Pergamino original 115x 160mm, letra gótica, buen estado de conservación. Conserva hijo azul del que pendía el sello. 
Éste es el único diploma que informa, sin género de dudas, de la participación de estos magnates en la guerra civil entre Sancho II y el futuro Alfonso III de Portugal. La Crónica de Cinco Reyes de Portugal afirma que Nuño González de Lara formaba parte de esta expedición. Asimismo la Crónica de Portugal de 1419 cita a Diego López de Haro, Nuño González de Lara, Rodrigo Gómez de Galicia, Ramiro y Rodrigo Froilaz y a don Fernando Iohannes de Limia entre los acompañantes del infante Alfonso, además de outros grandes senhores e muytas gentes ${ }^{55}$, sin embargo no hay ninguna prueba documental de la actuación del Lara en Leiría ${ }^{56}$.

Las fuerzas de Sancho II estaban muy debilitadas, no tenía el apoyo de la aristocracia eclesiástica de su reino, ni de las órdenes militares, ni podía hacer frente al dictamen papal. La guerra se redujo a pequeños enfrentamientos locales. José Varandas afirma que en el momento de la intervención del príncipe castellano, Sancho II tenía todo perdido, estima que sus fuerzas actuaron desesperadamente y que, poco después y alejado de la reina, don Sancho ya sólo podía dirigirse a la frontera con los restos de su ejército para abandonar su reino ${ }^{57}$.

El documento de excomunión no sólo informa sobre quiénes fueron los nobles que acompañaron al infante de Castilla, sino que también relata que Rodrigo Froilaz y Fernando Iohannes habían cometido rapiñas en el territorio de la sede de Braga. Se desconoce el momento exacto en el que fueron efectuadas, no obstante se enmarcan en el contexto de usurpaciones de bienes y ataques a las propiedades eclesiásticas de las que se quejaron los obispos de Oporto y Braga ante el Papa, y que fueron uno de los principales motivos para la deposición de Sancho II. Además, el hecho de que los obispos de Braga y Coimbra escribieran a los franciscanos de Guarda y Covilhã hace pensar que, en su retirada, las huestes del príncipe castellano se encontraran en estas tierras.

En efecto, parece que atravesaron estos territorios. Tras la batalla de Leiría, las fuerzas del infante don Alfonso llevaron consigo a Sancho II. La Crónica de Cinco Reyes de Portugal y la Crónica de Portugal de 1419 describen cómo Fernando García de Sousa, enviado por sus hermanos, se dirigió a Mo-

55 ALMEIDA CALADO, 1998: 132.

56 DE MAGALHÃES BASTO, 1945, Capítulo VII: 184. Esta crónica transmite varios errores cuenta cómo Sancho II se dirigió a Toledo donde se entrevistó con el infante Alfonso a quien pidió que le ayudase contra su hermano el conde de Boulogne. Don Alfonso le envio: "a Don Affonso de Molina, seu tio, irmaõ de seu padre cum muita gente pa o poer em posse do reino cae m sua companhia vinha Dioguo Lopes senõr de Biscaja e don Nuno Gonzalez de Lara e don Ruj Gomez de Galiza e dom Fernandi Anes de Lima e outros muitos grandes senhores e muitas gentes com elles entraraõ em Portugal e chagarõ tee Abeul quatro legoas de Leireia".

57 VARANDAS, 2004, 400.http://repositorio.ul.pt/bitstream/10451/593/1/16199_Bonus \%2520Rex\%2520ou\%2520Rex\%2520Inutilis.pdf (consulta 30 noviembre 2011). 
reira, cerca de Trancoso ${ }^{58}$, para hablar con don Sancho mientras estaba acampado junto al príncipe de Castilla, para entregarle la villa y el castillo y para recibirle como su señor natural. Sin embargo, don Sancho no fue a Trancoso, aunque sí lo hicieron, según el relato de las crónicas, don Diego López y don Nuño que, tras hablar con los hombres de la villa regresaron al campamento junto al infante castellano y Sancho II para dirigirse a Toledo ${ }^{59}$. Dudamos que Nuño González de Lara estuviera presente en esta expedición; sin embargo este relato informa del itinerario que siguieron las tropas leonesas en su regreso. Desde Leiría se dirigieron a Trancoso y probablemente atravesaron la frontera por alguna de las localidades cercanas de Pinhel, Castelo Rodrigo o Sabugal, entonces leonesas.

\section{LA SOLIDARIDAD FAMILIAR NOBILIARIA}

Tras certificar que Rodrigo y Ramiro Froilaz, Fernando Iohannes de Limia, Rodrigo Gómez de Traba y Diego López de Haro participaron junto al infante don Alfonso en la defensa de Sancho II de Portugal, es necesario descubrir cuáles eran los intereses familiares y políticos en el reino vecino que les llevaron a emprender esta aventura y el papel que desempeñaron en los preparativos y en la intervención militar. Para ello, utilizaremos la prosopografía como método de reconstrucción del parentesco y de la biografía política de cada uno de estos magnates.

La extensión de las redes de parentesco entre la nobleza de León y Portugal, con especial énfasis desde 1211, provocó que el conflicto portugués tuviera importantes ramificaciones en el territorio leonés, y que se pueda hablar del reflejo del conflicto lusitano entre la nobleza leonesa y gallega ${ }^{60}$. Rodrigo y Ramiro Froilaz, los hijos del conde Fruela Ramírez y de su última esposa Sancha Fernández- perteneciente a los Traba ${ }^{61}$ - representaban la nobleza de mayor raigambre, prestigio y poder del reino de León. Junto a su hermano, Diego Froilaz, se habían resistido a la llegada al trono leonés de Fernando III en 1230, pues temían que el reino girara en órbita castellana, como finalmente sucedió. No obstante, a partir de 1231, superados los primeros momentos de

${ }^{58}$ Probablemente Moreja, sea la actual Moreira del rey, en la actual fregresía del concelho de Trancoso, que se encuentra en el distrito de la ciudad de Guarda, próximo a la actual frontera con España.

${ }^{59}$ DE MAGALHÃES BASTO, 1945, IX: 186- 188.

${ }^{60}$ Sobre los lazos de parentesco y la nobleza instalada en la corte de León a partir de 1211, véase CALDERÓN MEDINA, 2011a: 200-240.

${ }^{61}$ Sancha Fernández era hija de Fernando Arias (hijo de Arias el Calvo) y de Teresa Vermúdez de Traba, lo que les emparenta con el conde Gomez González de Traba, padre de Rodrigo Gómez y con Juan Fernández de Limia, su tío. 
oposición al nuevo monarca, se integraron a su servicio y participaron en la empresa reconquistadora de Andalucía, aunque nunca alcanzaron los principales cargos palatinos ${ }^{62}$.

Rodrigo Froilaz estaba casado con doña Chamôa Gomes de Tougues, la hermana de Suero Gomes de Tougues, uno de los principales partidarios de Sancho II que murió en Leiría en la primavera de $1246^{63}$. Se desconoce el momento exacto en el que la pareja pudo contraer matrimonio, aunque es posible que fuera en torno a 1231 o en $1245^{64}$. En 1245 su hermano Ramiro Froilaz estaba casado con la noble castellana Aldonza González Girón ${ }^{65}$, con quien tuvo a Diego, Gonzalo, María, Sancho Ramírez ${ }^{66}$, y, probablemente a Aldonza ${ }^{67}$, abadesa de Otero de las Dueñas y su hermana Teresa Ramírez ${ }^{68}$. Todos ellos eran primos de Juan, Gonzalo, Sancha y Dordia Gil de Soverosa ${ }^{69}$, los hijos que su tía doña María González Girón había tenido de su matrimonio con don Gil Vasques de Soverosa, el principal valedor de Sancho II durante la guerra civil. Los hijos de María González y don Gil eran a su vez medio hermanos de doña Teresa Gil de Soverosa ${ }^{70}$, la última concubina de Alfonso IX; y de Mayor Guillén, la hija que su madre, María González Girón, había tenido de su relación con Guillén Pérez. Además en 1246 Mayor Guillén era la concubina del infante don Alfonso de Castilla.

En 1246 don Diego Froilaz ya había fallecido y por ello no participó en la campaña junto a su hermanos ${ }^{71}$, sin embargo es muy probable que aunque no aparezca en la documentación que se ha conservado, sí lo hiciera su hijo don Ramiro Díaz, que acompañaba con gran asiduidad a sus tíos en la corte de Fernando III. El vínculo de don Diego con la nobleza portuguesa era también muy estrecho, ya que su última esposa fue Aldonça Martins de Silva, antigua concubina de Alfonso IX y madre de don Rodrigo Alfonso, tío del infante Alfonso. Esta doña Aldonça Martins de Silva era sobrina del anterior obispo de Braga, don Estêvao Soares de Silva, y de doña Estevania Soares, la esposa de Martin Fernandes de Riba de Vizela; ambos habían sido los ayos de Sancho II y le fueron fieles hasta el final de sus días ${ }^{72}$.

${ }^{62}$ CALDERÓN MEDINA, 2011a: 473. CALDERÓN MEDINA, 2012: 135.

63 VENTURA, 1996: 109.

${ }^{64}$ Sobre este matrimonio. Véase CALDERÓn MEDINA, 2012 (en prensa).

65 FERNÁNDEZ FLÓREZ Y HERRERO DE LA FUENTE, 1999: docs. 557, 564.

${ }^{66}$ FERNÁNDEZ FLÓREZ Y HERRERO DE LA FUENTE, 1999: doc. 696.

${ }^{67}$ MARTÍNEZ MARTÍNEZ, 1997-2003: doc. 462.

${ }^{68}$ MARTÍNEZ MARTÍNEZ, 1997-2003: doc 728.

69 SOTTOMAYOR PIZARRO, 1999, III.

${ }^{70}$ Sobre esta mujer y las concubinas de Alfonso IX véase CALDERÓN MEDINA, 2011b (en prensa).

${ }^{71}$ Se conserva un diploma de 1236 de su viuda Aldonza junto a sus hijos. MARTÍNEZ MARTÍNEZ, 1997: doc.381.

${ }^{72}$ Sobre Aldonza Martins de Silva, véase CALDERÓN MEDINA, 2011 b (en prensa). 
En este grupo se encontraba el magnate gallego Rodrigo Gómez de Traba. Él era el noble con mayor poder en Galicia que en 1230 se había opuesto a Fernando III. Los libros de Linajes del conde don Pedro afirman que se opuso al nuevo rey de León hasta la conquista de Sevilla en 1248; sin embargo, en contra de estas noticias, se constata documentalmente que don Rodrigo se integró en el séquito de Fernando III a partir de marzo de 1231, poco después de que lo hicieran el resto de los leoneses que se opusieron a su llegada al trono ${ }^{73}$. Don Rodrigo era hijo del conde Gómez González de Traba al que sucedió al frente de su familia ${ }^{74}$. Fue tenente de las principales tenencias gallegas durante los reinados de Alfonso IX y Fernando III, y estaba casado con Mayor Alfonso, hija de Alfonso Téllez, El viejo, y de Teresa Sánches, hija bastarda de Sancho I de Portugal ${ }^{75}$.

El último de los magnates que con certeza formó parte de esta expedición es Fernando Iohannes de Limia. Era hijo de Juan Fernández de Limia, que había servido fielmente a Alfonso IX de León durante todo su reinado, ocupando la alferecía e importantes tenencias gallegas como Limia, Monterroso y Trastámara $^{76}$. Pero además había servido a Sancho II durante su minoría en numerosas ocasiones: en 1223 estaba en la corte de don Sancho junto a don Gil Vasques de Soverosa ${ }^{77}$, al año siguiente fue alférez real ${ }^{78}$ y, en 1225 , ocupó la mayordomía portuguesa ${ }^{79}$. Don Juan estaba casado con la portuguesa Berengária Afonso Baião, la madre de Fernando Iohannes. A pesar de ser un Baião, don Fernando trazó fuertes alianzas con los Soverosa a través de política matrimonial diseñada para sus hijos, habidos con doña Teresa Anes de Maia. Su hijo Fernando Fernández de Limia casó con Sancha Vasques de Soverosa, la hija de Vasco Gil ${ }^{80}$. Además su otro hijo, don Juan Fernández de Limia II, estaba casado con Sancha González Girón, hermana de doña Aldonza González Girón, la esposa de Ramiro Froilaz II.

La hermana de ambas, doña María González Girón ${ }^{81}$, era la esposa de Guillém Pérez de Guzmán y madre de Mayor Guillém, que por entonces era con-

${ }^{73}$ GONZÁLEZ, 1983, vol. II: doc. 311. Es el primer diploma emitido por Fernando III que confirma Rodrigo Gómez, mientras que el resto de los magnates leoneses se habían incorporado al servicio del nuevo rey de León tras el tratado de Benavente.

${ }^{74}$ El conde Gómez González era hijo de Gonzalo Fernández de Traba y, por lo tanto, nieto de conde Fernando Pérez de Traba; y, por lo tanto, primo de Teresa Vermúdez de Traba (la madre de Sancha Fernández, madre de Rodrigo y Ramiro Froilaz) que era hija de su tío Vermudo Pérez de Traba.

75 MATTOSO, 1980, LL, 13B2, 15B2, 57A1. CALDERÓN MEDINA, 2011a: 141 y 318.

${ }^{76}$ Don Juan fue. CALDERÓN MEDINA, 2011a: 146 y 502.

77 BERNARDINO, 2004: docs 1, 3, 11, 13.

78 BERNARDINO, 2004: docs. 20, 2.

79 BERNARDINO, 2004: docs 22, 24.

${ }^{80}$ SOTTOMAYOR PIZARRO, 2010: 53-73.

${ }^{81}$ GONZÁLEZ, 1980, vol 1: 158. 
cubina del infante Alfonso de Castilla. Sancha, Aldonza y María González eran hermanas de don Rodrigo González Girón, el mayordomo de Fernando III, que había participado en la conquista de Murcia junto al infante Alfon$\mathrm{so}^{82}$. Don Rodrigo había estado casado en primeras nupcias con María Froilaz, la hija de Fruela Ramírez y Urraca González de Traba ${ }^{83}$; por tanto, era medio hermana de Rodrigo Froilaz y de Ramiro Froilaz. Tras enviudar, don Rodrigo González Girón casó en 1243 con Teresa López de Haro ${ }^{84}$, medio hermana de Mencía López, la esposa de Sancho II de Portugal.

Entre los castellanos se encontraba don Diego López de Haro, hermano de la reina de Portugal doña Mencía López de Haro, por lo que se enfrascaba en esta aventura para defender los intereses de su hermana y de su cuñado, el legítimo rey de los lusos; pues si la pareja conseguía tener descendencia, sería su sobrino quien sucediera a Sancho II. Habitualmente se denomina castellano a don Diego porque su origen y patrimonio se situaba en Castilla, sin embargo no se puede obviar que Mencía y Diego López de Haro eran hijos de Lope Díaz de Haro y Urraca Alfonso, hija bastarda de Alfonso IX e Inés Íñiguez de Mendoza. La sangre real leonesa corría por sus venas, era primo del infante Alfonso de Castilla y sobrino de los hijos de Alfonso IX y Teresa Gil de Soverosa ${ }^{85}$.

Doña Mencía había estado casada con Álvar Pérez de Castro y, tras enviudar en 1240, casó con Sancho II de Portugal. Algunos sectores de la nobleza lusitana vieron con malos ojos este matrimonio del monarca, puesto que lo consideraban una estratagema de los magnates leoneses que se habían opuesto a la llegada al trono leonés de Fernando III de Castilla ${ }^{86}$. El matrimonio se efectuó entre 1241 y 1242, cuando Lope Díaz de Haro se había rebelado contra Fernando III $^{87}$, y en contra de la voluntad de doña Berenguela, que probablemente había ideado una alianza con otra mujer de más alta alcurnia para su sobrino portugués ${ }^{88}$. El matrimonio entre Sancho y Mencía ponía en peligro la estrategia de los partidarios del conde de Boulogne. En el momento de la intervención de este grupo nobiliario en Portugal, doña Mencía estaba cautiva en la fortaleza de Ourém, posiblemente ésta fue la espita que provocó la participación de don Diego López en el conflicto.

A pesar de que no hay constancia documental de la participación de Nuño González de Lara en la campaña portuguesa, las crónicas posteriores y Gil de

82 GONZÁLEZ, 1980, vol 1: 159.

${ }^{83}$ Esta Urraca González de Traba, era además hermana de Gómez González de Traba y, por lo tanto, tía de Rodrigo Gómez de Traba.

${ }^{84}$ TORRES FONTES, 1973: 28.

${ }^{85}$ CALDERÓN MEDINA, 2011: 116.

${ }^{86}$ VARANDAS, 2004: 313.

87 VARANDAS, 2004: 313.

${ }^{88}$ Estas son las noticias que transmite la Crónica de 1419. 
Zamora lo sitúan en la contienda; sin embargo creemos que no participó en ella, porque de haber sido así, hubiera sido excomulgado como el resto de los participantes. No obstante, el de Lara también tenía una importante relación familiar con este grupo magnaticio leonés y estaba emparentado con la nobleza portuguesa partidaria de Sancho II. Don Nuño estaba casado con doña Teresa Alfonso, hija bastarda de Alfonso IX ${ }^{89}$, habida de sus relaciones con Aldonça Martins de Silva ${ }^{90}$. Además era hijo de Gonzalo Núñez de Lara, el hijo de doña Teresa Fernández de Traba y, por tanto, era primo de Rodrigo Gómez de Traba. Dadas sus vinculaciones familiares no resultaría extraño que actuara en esta expedición en Portugal, pero no podemos constatarlo documentalmente.

Además de los nobles gallegos y leoneses, sabemos que el infante don Alfonso contó con la ayuda de Pedro Cornel-o Coronel-, llegado desde Aragón; pero, ¿quién es Pedro Cornel? Sospechábamos que este noble afincado en Aragón tendría un importante vínculo familiar con la nobleza portuguesa y leonesa que participó en esta campaña en ayuda de Sancho II, ya que el infante reclamó específicamente su ayuda ${ }^{91}$. No obstante, resulta complicado identificar a este personaje ya que coetáneamente vivían dos nobles homónimos en la corte aragonesa: Pedro Cornel, el mayordomo del rey, y Pedro Cornel, el esposo de Urraca Artal, sin embargo parece que ambos estaban emparentados entre sí y también con la nobleza portuguesa.

El conde don Pedro en su libro de linajes afirma que Pedro Corne ${ }^{92}$ desciende de doña María Rodrígues de Barbosa que casó en Aragón ${ }^{93}$. Esta María Rodrígues de Barbosa, era la esposa de Jimén de Urrea ${ }^{94}$, y hermana de Teresa Rodrígues Barbosa, la madre de Soero Gomes de Tougues y Chamôa Gomes de Tougues, esposa de don Rodrigo Froilaz. Pero además estaba emparentada con los Soverosa, ya que ambas ramas descendían de Gonçalvo Mendes de Sousa y de Urraca Sanches de Barbosa. De este matrimonio habían nacidos dos hijas: Elvira Gonçalves que casó son Suero Mendes de Tougues y, Teresa Gonçalves, que contrajo nupcias con Vasco Fernandes de Soverosa. Estas parejas eran los abuelos de Soero y de Chamôa Gomes de Tou-

${ }^{89}$ MARTÍNEZ MARTÍNEZ, 1997-2003: doc. 495

90 CALDERÓN MEDINA, 2011: 119.

${ }^{91}$ Quiero agradecer la ayuda del profesor Carlos Laliena Corbera en la identificación de este individuo.

92 MATTOSO, 1980: LL 41 A41.

${ }_{93}$ MATTOSO, 1980: LL37C5.Dona Maria Rodrigues. Filha de dom Rui Vaasques e da condesa dona Toda, foi casada en Aragom, e decendeo dela dom Simon d'Urrea, e Pero Cornel e Reimondo de Cardona, o que veo a Portugal e dona Berengaria de Cardona.

${ }^{94}$ En 1249 doña María, viuda de don Jimén de Urrea hace una concordia con su hijo Gil de Urrea que hereda el titulo familiar. http://www.jaumeprimer.uji.es/cgi-bin/noticia.php? referencia=01012010 (fecha de consulta: 27 de diciembre de 2011) En esta composición está presente el infante don Pedro de Portugal y Pedro Cornel. 
gues y de sus primos, los hijos de doña Maria Rodrigues, y de don Martín Gil de Soverosa y sus hermanos, respectivamente.

La información que aporta el conde don Pedro sobre la ascendencia de Pedro Cornel es insuficiente para establecer el parentesco exacto que tenía con María Rodrígues de Barbosa. Sabemos que con Jimén de Urrea doña María Rodrígues tuvo al menos cinco hijos: Jimén, Pedro, Sancha, Guillerme y Eva $^{95}$. Alguna de sus hijas era la madre de Ramón de Cardona, que en 1306 reclamó los bienes que le pertenecían de la parte de su abuela María Rodrígues en el coto de Santa Clara de Entre-os-Ríos ${ }^{96}$. Estos datos certifican las palabras del conde don Pedro que afirmaba que de esta María Rodrígues de Barbosa descendían los Urrea y los Cardona. Pero además el conde establecía que también descendían de ella los Cornel aragoneses. El nobiliario aragonés estima que Pedro Cornel, podría ser hijo de otra de las hijas de María Rodrígues ya que éste llama tío a don Jimén de Urrea II.

El nobiliario de Aragón afirma que «de don Pedro Cornel, hijo de Ximeno Cornel y de don Pedro Cornel, padre de Toda Pérez, muxer de don Ximeno de Urrea se hace mención que eran vivos en la era de 1314, como parece por el testamento del mismo don Ximeno de Urrea del mismo año. Y así se puede colegir que don Pedro Cornel el mayordomo fue sobrino de don Ximeno el consejero del rey don Jaime, y suegro de don Ximeno de Urrea y primo de don Pedro Cornel, marido de Urraca Artal ${ }^{97}$. (....) Así se puede colegir que don Pedro Cornel era sobrino de don Ximeno de Urrea II y no es el mismo que casó con Urraca de Artalı ${ }^{98}$. De aquí se deduce que nuestro Pedro Cornel era nieto de María Rodrígues de Barbosa.

Gracias a la combinación de la información que aportan distintas fuentes tanto lusitanas como aragonesas, podemos conocer la vinculación de Pedro Cornel con la nobleza lusa partidaria de Sancho II. Sin duda, el infante don Alfonso de Castilla en 1247 conocía el parentesco exacto que unía a Pedro Cornel con los Tougues y los Soverosa, que además tenían estrechos vínculos de parentesco con los Flaínez, los Limia, los González Girón y los bastardos de Alfonso IX, y por ello insistió en que don Pedro Cornel se dirigiera a Portugal para defender los intereses de sus parientes y del rey legítimo. Muy probablemente fueron ellos quienes instaron al infante a que apelara a la ayuda de su pariente aragonés.

${ }^{95}$ Se conserva el testamento que Jimén de Urrea hizo en 1240 antes de partir a la campaña de Valencia. http://www.jaumeprimer.uji.es/cgi-bin/noticia.php?referencia=18122009 (última consulta 28 de noviembre 2011)

${ }^{96}$ ANTT. OFM, Santa Clara do Porto, mç 51, doc 14. La partición de los bienes se hizo efectiva tres años después en 1309. ANTT. OFM, Santa Clara do Porto, mç 51, doc 15.

97 GARCÉS DE CARIÑENA, 1983: 56.

98 GARCÉS DE CARIÑENA, 1983: 57. 
Pero si es importante analizar qué nobles leoneses participaron en la campaña, también lo es observar a quiénes, formando parte de este grupo nobiliario leonés que confirmaba en bloque los diplomas de Fernando III, no lo hicieron, y descubrir cuáles fueron sus motivos.

No hay ningún indicio de que don Martín Alfonso, hijo de Teresa Gil de Soverosa y Alfonso IX participara en la contienda. Era un Soverosa y, por lo tanto, lo lógico es que hubiera participado junto a sus tíos Martin y Vasco Gil de Soverosa en el bando defensor de Sancho II. Además era mandante de Salamanca y otras zonas próximas a la frontera lusa, por lo que hubiera sido un importante apoyo logístico ${ }^{99}$; sin embargo, creemos que don Martín tenía intereses enfrentados. Él era un Soverosa, hijo del rey de León, su madre todavía tenía numerosos intereses en Portugal ${ }^{100}$, pero estaba emparentado con los Sousa y los Alburquerque a través de su matrimonio con doña María Mendes de Sousa. Doña María Mendes era nieta de Teresa Sanches, la hija bastarda de Sancho I de Portugal, que casó con Alfonso Téllez de Meneses ${ }^{101}$. Doña María Mendes era prima de don Alfonso Téllez, y de João y Martin Alfonso de Alburquerque, que estaban entre los partidarios del conde de Boulogne. Por tanto, María encarnaba la alianza entre las dos principales familias partidarias del futuro Alfonso III. Tal vez don Martín viera sus intereses enfrentados y, probablemente por ello prefirió abstenerse de participar abiertamente en el conflicto que, en Portugal, estaba enfrentando a sus consanguíneos con sus parientes afines.

Tampoco se registra la presencia de Rodrigo Alfonso, el hijo de Alfonso IX y Aldonça Martins de Silva ${ }^{102}$, en las tropas que acompañaron al futuro Alfonso X. Don Rodrigo estaba casado con Inés Rodríguez, la hija de Teresa Froilaz, sobrina, por tanto de Ramiro y Rodrigo Froilaz. Además su suegra Aldonça había estado casada con Diego Froilaz. Es cierto que Rodrigo Alfonso acompañó a su sobrino el infante en su periplo por el reino en busca de recursos suficientes para acometer su propósito; sin embargo no hay noticias de su participación en la campaña militar. Resulta extraño, puesto que estaba relacionado con los Riba de Vizela, que eran unos de los principales apoyos de don Sancho de Portugal, y con los Flaínez.

Tras desbrozar esta maraña de parentesco podría decirse que en ella están implicadas varias familias: los Flaínez, los Limia y los Traba, pero también los Haro y los Girón castellanos, los Soverosa, los Tougues, los Riba de Vizela portugueses y tres ramas de la línea bastarda de descendencia de Alfonso IX de León; es decir, los hijos habidos con Inés Íñiguez de Mendoza y las damas lusitanas Aldonça Martins da Silva y Teresa Gil de Soverosa, que eran,

\footnotetext{
${ }^{99}$ CALDERÓN MEDINA, 2011a: 121-122.

${ }^{100}$ Sobre el patrimonio de doña Teresa véase. CALDERÓN MEDINA, $2011 \mathrm{~b}$ (en prensa).

${ }^{101}$ SOTTO MAYOR PIZARRO, 1999, 1: 167.

102 CALDERÓN MEDINA, 2011a: 119.
} 
por tanto, tíos y primos de Alfonso de Castilla, futuro Alfonso X. La tupida red parentelar tejida por estas familias nobiliarias es la clave que explica la participación de la nobleza leonesa y gallega en la guerra civil lusitana. Sin duda, ante la grave situación que estaban viviendo los Soverosa, Tougues y Riba de Vizela por la deposición del rey legítimo, a la que no podían hacer frente y por la lucha con las tropas del conde de Bolougne y de Pedro de Portugal, pidieron desesperadamente ayuda a sus parientes leoneses, gallegos y aragoneses.

Martín Gil de Soverosa fue sin duda la pieza clave. Él era el principal consejero de Sancho II y quien diseñó la estrategia política y militar de El Capelo durante la crisis. Posiblemente fue él quien apeló a la ayuda de su familia gallega y a partir de entonces, el resto de los nobles leoneses y gallegos se fueron adhiriendo a la causa como piezas de dominó, puesto que los intereses encadenados de sus familiares les arrastraban a movilizarse en ayuda de sus parientes lusos.

\section{CONCLUSIONES}

En las páginas iniciales planteábamos la hipótesis de que la presión de la nobleza leonesa y gallega fuera uno de los motivos de la participación del infante Alfonso de Castilla en la guerra civil portuguesa. Para demostrarlo optamos por analizar el parentesco que unía a los nobles de ambos reinos que, ante una situación excepcional de peligro para sus intereses, apelaron a su unión en defensa del interés común y de los derechos del rey legítimo de Portugal.

Consideramos que el estudio del panorama nobiliario en este periodo puede explicar numerosos aspectos de la campaña llevada a cabo en Portugal y del contexto en el que se desarrolló. En primer lugar, la negativa de Fernando III. El rey se opuso tajantemente a la intervención en la guerra portuguesa. Tradicionalmente se ha explicado su negativa porque su objetivo principal era la conquista del sur musulmán y no estaba dispuesto a que las fuerzas económicas y militares se vieran mermadas por la participación en otros asuntos de menor relevancia para los intereses de la corona castellana. Asimismo parece que Fernando III quería evitar un enfrentamiento con el Papado, con el que tenía óptimas relaciones.

Sin embargo, es posible que su relación con la aristocracia leonesa explique su negativa. Dadas las vinculaciones parentelares que la nobleza leonesa mantenía con los principales partidarios de Sancho II de Portugal, parece que fueron ellos quienes ante la alarma lanzada por sus parientes comenzaron a movilizarse para ayudar a El Capelo y buscaron el manto protector y legitimador de la monarquía leonesa. Es probable que en primer lugar, los Flaínez, 
Fernando Iohannes de Limia y Rodrigo Gómez de Traba intentaran persuadir al monarca; no obstante su relación personal con el rey nunca fue buena, parece que siempre tuvieron recelos hacia el hijo de Alfonso IX, y don Fernando se negó.

Estos nobles leoneses y gallegos se habían opuesto a su llegada al trono leonés en 1230; pero, superados los primeros momentos de oposición, se integraron a su servicio en 1231, aunque ocupaban un papel secundario en la corte. Desde su llegada al trono de León Fernando III había relegado a un segundo plano al reino y a su nobleza, que ya no volvió a ocupar los principales cargos palatinos y, posiblemente, vio mermados sus ingresos. En contrapartida, esta nobleza había reforzado sus vinculaciones con Portugal desde 1230, probablemente como un espacio en el que lograr nuevos ingresos y aumentar su poder político, en un tiempo en el que el poder regio luso estaba muy debilitado y en el que Martín Gil de Soverosa, cuya familia tenía estrechas vinculaciones con la monarquía y la nobleza leonesa desde el reinado de Fernando $\mathrm{II}^{103}$, manejaba la política regia.

En 1241, cuando los Haro estaban enfrentados a Fernando III, se materializó el matrimonio entre Sancho II y Mencía López de Haro. Esta unión se hizo en contra de la voluntad de doña Berenguela y de don Fernando, tal vez porque esta alianza conllevaba el fortalecimiento de los lazos que unían a la nobleza leonesa con la monarquía lusa, pero también estrechaba sus vínculos con la poderosa nobleza portuguesa, que dominaba el ánimo de El Capelo. Hermenegildo Fernandes apunta a que quizá Berenguela, dado que don Sancho tenía ya treinta años y no tenía descendencia, hubiera planeado otro futuro al reino de Portugal y, por ello, se oponía a este enlace ${ }^{104}$. Es factible que este grupo magnaticio fomentara este enlace como un elemento a través del que manejar al débil don Sancho y poder ampliar sus intereses en Portugal, puesto que ya contaban con la estructura familiar que necesitaban para ello.

Además, desde 1240 esta nobleza había estrechado su vinculación con el hijo de Fernando III que se encargaba de la dirección del reino leonés y ocupaba las tenencias de sus principales ciudades. Posiblemente desde entonces se habían aglutinado lazos afectivos con don Alfonso que tenía un profundo vínculo familiar con algunos de los principales magnates leoneses. Es probable que a partir de 1245 este grupo nobiliario pensara que si lograba revertir la situación de Sancho II a través de una ambiciosa campaña militar, obtendría una apetecible recompensa que le permitiría contrarrestar el poder que

${ }^{103} \mathrm{Su}$ abuelo Vasco Fernandes de Soverosa sirvió a Fernando II desde 1185. Don Martín era hermano de Teresa Gil de Soverosa, la última concubina de Alfonso IX, que continuaba en tierras gallegas. Sobre los Soverosa en León véase, CALDERÓN MEDINA, 2011a: 212- 217. CALDERÓN MEDINA, $2011 \mathrm{~b}$.

${ }^{104}$ FERNANDES, 2006: 254. 
había perdido junto a Fernando III, y, para ello los nobles buscaron el apoyo del infante don Alfonso que tenía intereses patrimoniales en Portugal, además de una buena relación personal con Sancho II.

Sus intereses parecían haber confluido. Aunque no podemos esclarecer los objetivos del infante Alfonso, sospechamos que iban más allá de socorrer a Sancho II porque su actividad y la de los nobles que le acompañaron para lograr recursos fue frenética y desesperada. Tal vez el infante Alfonso intentaba postularse al trono en un momento en que la curia pontificia estaba pensando en varios candidatos: el infante Fernando de Serpa, Pedro Sanches, señor de Mallorca, y Alfonso, conde de Boulogne. Tras el nombramiento del conde de Boulogne como curador del reino, Inocencio IV contestó al infante castellano que, si Sancho II lograba restituir la paz y la justicia, le devolvería el gobierno. Es a partir de entonces cuando se comienza a pensar en una intervención militar, muy probablemente con intención de conquistar el reino, aunque tal vez no fuera para sentarse en el trono, sino para extender el vasallaje a todo el reino de Portugal, como posteriormente sucediera con el Algarbe.

La historiografía tradicional ha tratado la intervención de Alfonso de Castilla en la guerra civil lusitana como una campaña que parte de su propia iniciativa, enfrentándose a su padre, en defensa de los derechos de Sancho II. Sin embargo, tras analizar el contexto nobiliario, consideramos que es posible afirmar que se trata de una campaña de iniciativa nobiliaria; es decir, que ante la llamada de Martín Gil de Soverosa, sus parientes leoneses y gallegos se movilizaron para aunar fuerzas e ir en su defensa. Probablemente intentaron buscar el apoyo de Fernando III pero, ante su negativa, consiguieron la ayuda del infante don Alfonso que estaba vinculado a tierras leonesas y tenía intereses patrimoniales en Portugal. Es factible que el infante se convirtiera así en el capitán de esta expedición. Los nobles portugueses y leoneses también le instaron a solicitar el apoyo de sus parientes, los Cornel aragoneses, en su intento de conseguir todos los recursos necesarios para defender los intereses de sus consanguíneos y afines, partidarios del legítimo rey de los lusos. Para llevar a cabo esta expedición se buscó el amparo de la monarquía castellana y aragonesa, sin embargo Fernando III y Jaime I rehusaron participar, aunque sus primogénitos capitanearon las huestes nobiliarias que entraron en Portugal, requeridas por sus parientes portugueses para defender su estatus y los derechos del depuesto rey lusitano.

Leontina Ventura apunta la posibilidad de que durante el exilio de Sancho II en Toledo, se pudiera estar gestando una campaña de conquista, sin embargo la muerte de El Capelo acabó con las expectativas y legitimó la posición de Alfonso III como rey de Portugal. Las consecuencias para los participantes en esta intervención en Portugal no fueron graves. En 1250 la excomunión lanzada por Inocencio IV fue levantada. Asimismo tras la llegada al trono portugués de Alfonso III, los leoneses que se habían enfrentado a él y continua- 
ban teniendo intereses en su reino, no sufrieron represalias. Así Rodrigo Froilaz continuó gestionando los bienes de su esposa Chamôa Gomes de Tougues, y en 1258, para resarcir las malffetrias he danpnos que ffiziemos enno regno de Portogal ${ }^{105}$, fundó el monasterio de Santa Clara de Entre-os-ríos.

Este trabajo pone al descubierto el poder de la sangre, la fuerza del parentesco y la existencia de la fuerte conciencia de pertenencia a un grupo familiar extenso que tenía la nobleza. Se ha podido observar la tupida red de parentesco que se extiende por cuatro reinos peninsulares y que constituye un poderoso sustrato nobiliario ibérico, bien organizado y cohesionado, capaz de intervenir en las relaciones políticas entre reinos y, como se ha visto, de implicar a tres monarquías. La solidaridad familiar fue una poderosa arma nobiliaria, a la que se apelaba en momentos de grave peligro para los intereses comunes. La cohesión familiar estaba posiblemente por encima del servicio a su señor natural; no se dudaba en socorrer a los parientes en momentos de acuciante necesidad, a pesar de la negativa del rey al que servían.

105 CALderón MedinA, 2012, doc 2. 

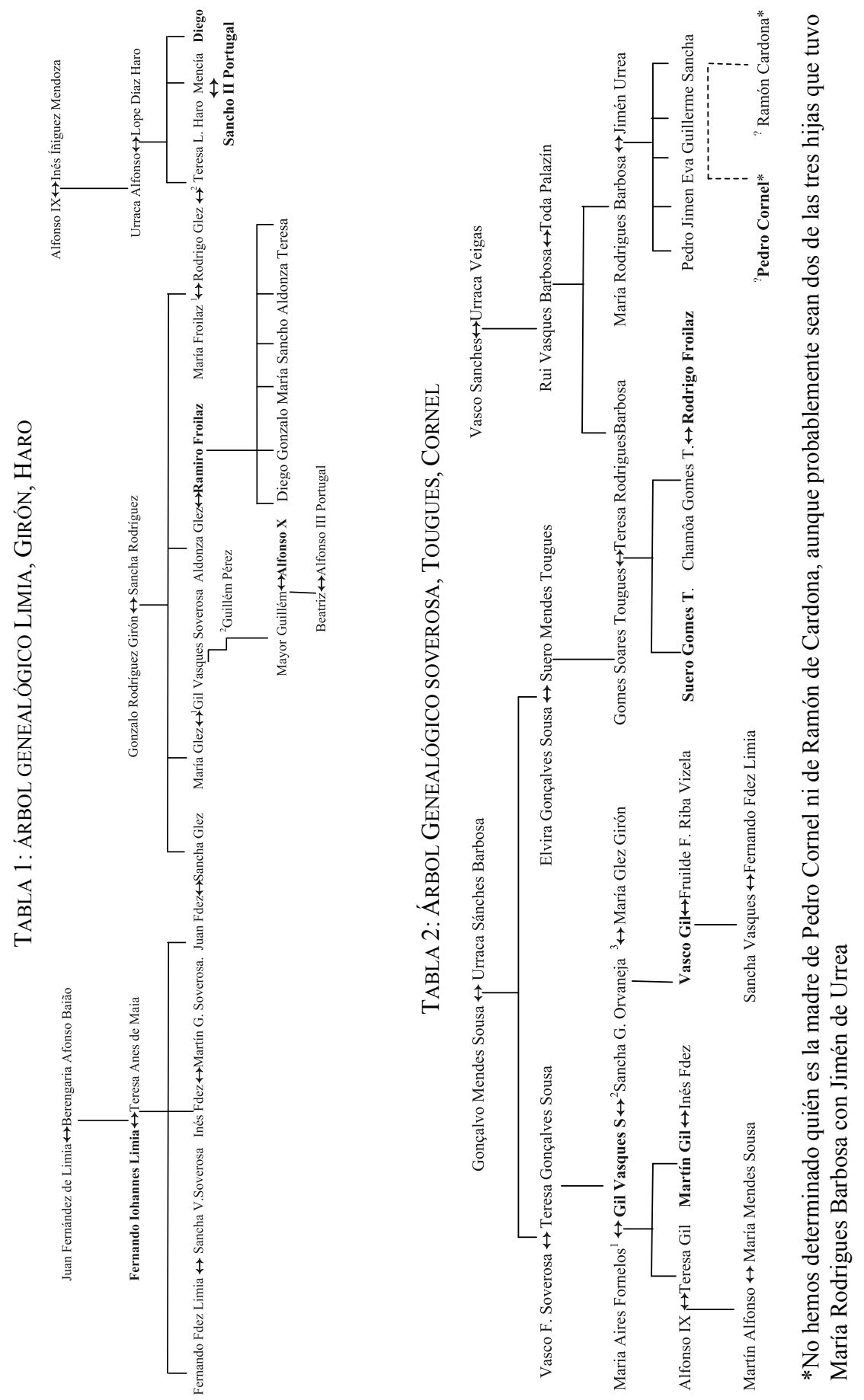

Hispania, 2013, vol. LXXIII, nº. 245, sept.-diciembre, págs. 617-646, ISSN: 0018-2141, e-ISSN: 1988-8368, doi: 10.3989/hispania.2013.016 


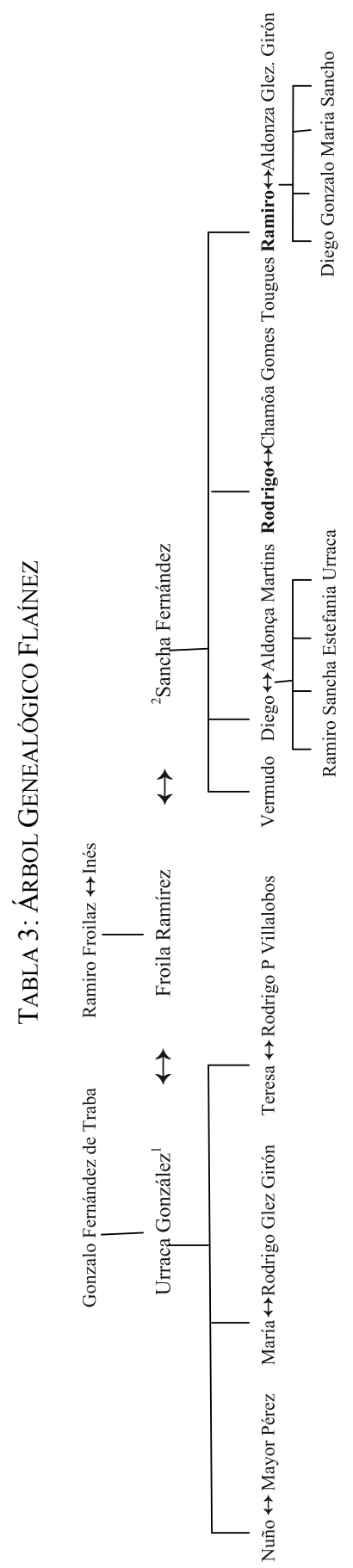

Hispania, 2013, vol. LXXIII, no ${ }^{\circ}$ 245, sept.-diciembre, págs. 617-646, ISSN: 0018-2141, e-ISSN: 1988-8368, doi: 10.3989/hispania.2013.016 


\section{BIBLIOGRAFÍA}

Almeida Calado, Adelino (ed.), Crónica de Portugal de 1419, Aveiro, Universidade de Aveiro, 1998.

Ballesteros Beretta, Alfonso, Alfonso Xel Sabio, Barcelona, El Albir, 1984.

Barrios, Ángel, Documentación medieval del archivo Municipal de Ciudad Rodrigo, Salamanca, Universidad de Salamanca, 1988.

Bernardino Gonçalves Pereira, Virginia, Sancius Secundus Rex Portugalensis. A Chanceleria de D. Sancho II (1233- 1248), Tese de maestrado apresentada na Universidade de Coimbra, Coimbra 2003.

Brea, Mercedes (coord.), Lírica profana galego-portuguesa: corpus completo das cantigas medievais, con estudio biográfico, análise retórica e bibliografía específica, Santiago de Compostela, Centro de Investigaciones Lingüísticas e Literarias Ramón Piñeiro, 1996.

Calderón Medina, Inés, Cum magnatibus regni mei. La nobleza y la monarquía leonesas durante los reinados de Fernando II y Alfonso IX de León, (1157-1230), Madrid, CSIC, 2011a.

Calderón Medina, Inés, "Las otras mujeres del rey. El concubinato regio en el reino de León (1157-1230)", en José Carlos Ribeiro Miranda (coord.), Seminario Medieval 2009- 2011, Oporto, 2011 b (en prensa).

Calderón Medina, Inés "Rodrigo Froilaz, el esposo de Chamôa Gomes de Tougues. Los fundadores de Santa Clara de Entre-os-ríos", Revista População e Sociedade, 20 (Porto, 2012) (en prensa).

De Magalhães Basto, Arthur (ed), A Crónica de Cinco Reis de Portugal, Porto, Livraria Civilização Editora, 1945.

De Manuel Rodríguez, Miguel, Memorias para la vida del santo rey don Fernando III. Madrid, Imprenta de la Viuda de don Joaquin Ibarra, 1800.

Fernandes, Hermenegildo, D. Sancho II. Tragédia, Lisboa, Circulo de Leitores, 2006.

Fernández Catón, José María, Colección documental del Archivo de la Catedral de León (1188-1230), León, Centro de Estudios e Investigación "San Isidoro", 1991.

Fernández Flórez, José Antonio, y Herrero de la Fuente, Marta, Colección documental del monasterio de Santa María de Otero de las Dueñas, León, Centro de Estudios e Investigación "San Isidoro", 1999.

Fita Colomer, Fidel "Biografías de San Fernando y de Alfonso el Sabio por Gil de Zamora" Boletín de la Real Academia de la Historia, 5 (Madrid, 1884): 308-328.

Garcés de Cariñena, Pedro, Nobiliario de Aragón, Zaragoza, Anubar Ediciones, 1983.

García Fernández, Manuel, "La política internacional de Portugal y Castilla en el contexto peninsular del tratado de Alcañices: 1267- 1297. Relaciones diplomáticas y dinásticas” en IV Jornadas luso-españolas de história medieval (2), Oporto, 1998, 901- 943.

García Tato, Isidro, Las encomiendas gallegas de la Orden Militar de San Juan de Jerusalén. Estudio y edición documental, CSIC, Santiago de Compostela, 2004. 
Gonzaga de Azevedo, Luis, História de Portugal, Lisboa, Edições “Bíblion”, 1944. González Jiménez, Manuel. Alfonso X (1252-1284): Historia de un reinado. Col. Reyes de Castilla y León, Palencia, Diputación de Palencia, 1999.

González Jiménez, Manuel, “Alfonso X y Portugal”, Alcanate: Revista de Estudios Alfonsíes, 4 (Sevilla, 2004- 2005): 19-34.

González Jiménez, Manuel, "Las relaciones entre Portugal y Castilla durante el siglo XIII" en Actas de las Jornadas Luso- Espanholas de História Medieval. As relacões de frontera no século de Alcanices, Porto, 2000: 1-24.

González Jiménez, Manuel. Alfonso X el Sabio, Madrid, Ariel, 2004.

González Jiménez, Manuel. Fernando III el Santo. El rey que marcó el destino de España. Fundación José Manuel Lara, 2006.

González Jiménez, Manuel. Crónica de Alfonso X, Murcia, Real Academia Alfonso X El Sabio, 1999.

González, Julio, Reinado y Diplomas de Fernando III, I, Monte de Piedad y Caja de Ahorros, Madrid, 1980.

González, Julio, Reinado y Diplomas de Fernando III, II, Monte de Piedad y Caja de Ahorros, Madrid, 1983.

González, Julio, Reinado y Diplomas de Fernando III, III, Monte de Piedad y Caja de Ahorros, Madrid, 1986.

Hernández Segura, Amparo (ed.), Crónica de la población de Ávila, Valencia, Anubar Ediciones, 1966.

Martínez Martínez, Martín, Cartulario de Santa María de Carracedo (I). Monasterio de Santa María de Carracedo, León, Instituto de Estudios Bercianos, 1197-2003.

Mattoso, José y Piel Joseph, (eds), Portugaliae Monumenta Historica a saeculo octavo post Christum usque ad quintum decimum, nova série (I). Livros Velhos de Linhagens; II (2). Livro de Linhagens do Conde D. Pedro. Lisboa Editora, Lisboa 1980.

Mattoso, José, “A crise de 1245”, Revista História das Ideias, 6, (Coimbra, 1984): 7- 25.

Mattoso, José, "As relações de Portugal com Castela no reinado de Afonso X, el Sabio", en Obras Completas Jose Mattoso, vol 6, Lisboa, Circulo de Leitores, 2001: 59-77.

Mattoso, José, “Ourém e D. Mécia Lopes de Haro”, en Mattoso, José, A Nobreza Medieval Portuguesa, Lisboa, Ed. Estampa, 1981: 279-283.

Mattoso, José, História de Portugal. A monarquia feudal (1096-1480), Lisboa, Editorial Estampa, 1993.

Mondéjar, Marqués de, Memorias históricas del rey D. Alfonso el Sabio, i observaciones a su crónica. Madrid, Imprenta de Antonio de Sancha, 1777, XVI: 24- 27.

Salvador Martínez, H. Alfonso X, el Sabio. Una biografía, Madrid, Ediciones Polifemo, 2003.

Sottomayor Pizarro, José Augusto, Linhagens medievais portuguesas. Genealogías e estratégias, Porto, 1999.

Sottomayor Pizarro, José Augusto, «Os Limas: da Galicia a Giela (séc. XII a XV)», en Actas do II Congresso internacional Casa nobre: Um património para o futuro, Arcos de Valdevez, 2010: 53-73. 
Torres Fontes, Juan. Colección de documentos para la historia del Reino de Murcia. III. Fueros y privilegios de Alfonso X el Sabio al Reino de Murcia, Murcia, Academia Alfonso X el Sabio, 1973.

Valls- Taberner Fernando. "Relacions familliars i politiques entre Jaume I el Conqueridor i Anfos el Savi", Bulletin Hispanique, 21/1 (Burdeos, 1919): 9-52.

Varandas, José Manuel, Rex bonus, rex inutilis. Tese de doutoramento apresentada na Faculdade de Letras de Universidade do Lisboa, Lisboa 2004.

Ventura, Leontina; Gomes, Saul António, "Leiria na crise de 1245-1248. Documentos para uma revisão crítica", Revista Portuguesa de História, XXVIII (Coimbra, 1993): 168-197.

Ventura Leontina, "A Crise de meados do século XIII", en de Joel Serrão e A,H. de Oliveira Marques, (dir), Nova História de Portugal (III). Portugal em definição de fronteiras.Do condado portucalense à crise do século XIV, Lisboa, Palas Editores, 1996, 104-123.

Ventura, Leontina, Afonso III, Lisboa, Circulo de Leitores,2006.

Recibido: 24/01/2012

Aceptado: 08/12/2012 